\title{
Oxidoreductases in Glycoprotein Glycosylation, Folding, and ERAD
}

\author{
Chaitanya Patel ${ }^{1,2} \mathbb{D}^{\circ}$, Haddas Saad ${ }^{1,2}$, Marina Shenkman ${ }^{1,2}$ and Gerardo Z. Lederkremer ${ }^{1,2, *}$ \\ 1 The Shmunis School of Biomedicine and Cancer Research, Cell Biology Division, George Wise Faculty of Life \\ Sciences, Tel Aviv University, Tel Aviv 69978, Israel; chaitanyspatel@gmail.com (C.P.); \\ s.haddas@gmail.com (H.S.); shenk@tauex.tau.ac.il (M.S.) \\ 2 Sagol School of Neuroscience, Tel Aviv University, Tel Aviv 69978, Israel \\ * Correspondence: gerardol@tauex.tau.ac.il
}

Received: 31 August 2020; Accepted: 18 September 2020; Published: 22 September 2020

\begin{abstract}
N-linked glycosylation and sugar chain processing, as well as disulfide bond formation, are among the most common post-translational protein modifications taking place in the endoplasmic reticulum (ER). They are essential modifications that are required for membrane and secretory proteins to achieve their correct folding and native structure. Several oxidoreductases responsible for disulfide bond formation, isomerization, and reduction have been shown to form stable, functional complexes with enzymes and chaperones that are involved in the initial addition of an N-glycan and in folding and quality control of the glycoproteins. Some of these oxidoreductases are selenoproteins. Recent studies also implicate glycan machinery-oxidoreductase complexes in the recognition and processing of misfolded glycoproteins and their reduction and targeting to ER-associated degradation. This review focuses on the intriguing cooperation between the glycoprotein-specific cell machineries and ER oxidoreductases, and highlights open questions regarding the functions of many members of this large family.
\end{abstract}

Keywords: PDI; oligosaccharyltransferase; calnexin; ER quality control; mannosidase; ERAD

\section{Introduction}

Secretory and membrane proteins are folded in the endoplasmic reticulum (ER) with the aid of various molecular chaperones and oxidoreductases, which catalyze oxidation and reduction reactions on their cysteine residues. The great majority of the secretory proteins are glycosylated, mostly by addition of one or more $\mathrm{N}$-linked oligosaccharides covalently attached to asparagine (Asn) sidechains. Nascent N-linked glycoproteins possess a large oligosaccharide precursor, $\mathrm{Gl}_{3} \mathrm{Man}_{9} \mathrm{GlcNAc}_{2}$, which is later sequentially trimmed. Protein folding and acquisition of the correct native structure depends on the addition and proper processing of these sugar chains. Defects in N-linked glycosylation can cause a number of inherited diseases named congenital disorders of glycosylation. The ability of mammalian cells to correctly identify and degrade misfolded secretory proteins is crucial for their correct function and survival. An inefficient disposal mechanism results in the accumulation of misfolded proteins and consequent ER stress.

Disulfide bond formation is one of the most important modifications affecting secretory protein folding, which is catalyzed by the disulfide isomerase (PDI) family of proteins. Most glycoproteins have disulfides, which are present in $78 \%$ of the secretory proteins [1]. The oxidative environment in the ER enables ER-resident oxidoreductases to facilitate disulfide bond formation, which stabilizes protein structures. Proper redox conditions in the ER, together with regulation of calcium homeostasis, are vital for the functions of many luminal pathways and the maintenance of homeostasis. 
Oxidoreductases are enzymes involved in the protein folding process, which are responsible for modifying exposed cysteine thiol groups by oxidation, reduction, and isomerization. The oxidoreductases contain domains structurally similar to cytosolic thioredoxin, called thioredoxin-like domains. The reaction of disulfide bond formation is assisted by exchange of two electrons between the cysteine of the substrate protein and cysteines in a catalytic Cys-X-X-Cys motif in the thioredoxin-like domain of the oxidoreductases (reviewed by Robinson and Bulleid in this Special Issue [2]). Over 20 oxidoreductases have been identified in the ER, of which PDI, also known as P4HB/PDIA1, is the best characterized. Some of these enzymes contain more than one thioredoxin-like domain, including some that are not catalytic (e.g., PDI contains two active and two non-catalytic thioredoxin-like domains). The enzymes are soluble ER luminal proteins, except for the five members of the TMX subfamily, which have a transmembrane domain (reviewed by Guerra and Molinari in this Special Issue [3]). The oxidoreductases catalyze disulfide bond formation by oxidizing the cysteine residues of the folding protein. The reduced oxidoreductase molecules are then re-oxidized by several oxidases-Ero1 $\alpha$, Ero1 $\beta$, Prx4, GPX7, and GPX8 [4-8]. Ero1 $\alpha$ is the main oxidase involved, transferring a pair of electrons to molecular oxygen in a flavin-mediated reaction to yield hydrogen peroxide. Several of the oxidoreductases have the capability, and in some cases a preference, to reduce disulfide bonds. The stability of the active-site disulfides determines the function of the PDI family member in reduction or oxidation. Comprehensive reviews of the oxidoreductases and their mechanism of action can be found in [9-11].

There is also a series of ER-resident oxidoreductases that are selenoproteins. Selenoproteins are proteins that incorporate an atom of selenium instead of sulfur in one or more cysteines, which are then called selenocysteine, abbreviated as Sec (U). Incorporation of Sec into a selenoprotein is a result of transfer from a selenocysteine-specific tRNA, which decodes an UGA codon in the mRNA. Selenoproteins intervene in numerous physiologic pathways, such as immune responses, antioxidant defense, redox signaling, and thyroid hormone metabolism. Some of the selenoproteins function as oxidoreductases, containing thioredoxin-like domains with one or more selenocysteines instead of cysteine in a catalytic Cys-X-X-Sec or similar motif [12-14].

In addition to their catalytic activity in disulfide bonding, many of the oxidoreductases were shown to recognize hydrophobic pockets in their substrate proteins, and thus they are in fact folding sensors. They participate in the recognition of misfolded glycoprotein domains during sugar chain trimming and creation of what was termed the glycan code for targeting to ER-associated degradation (ERAD) [15]. The oxidoreductases escort and functionally interact with glycoproteins, from their translocation into the ER and glycosylation to late stages of productive folding or targeting to ERAD. Several oxidoreductases have been found in recent years to associate functionally with the glycan recognition and processing machineries in the ER, which is the focus of this review.

\section{Oxidoreductases in the Oligosaccharyltransferase Complex}

The majority of secretory proteins are N-glycosylated, a reaction that occurs mostly co-translationally in higher eukaryotes. In the ER lumen, the translocating proteins are exposed to a variety of enzymes and chaperones that promote protein maturation through both folding and post-translational modifications. At the luminal side of the Sec61 translocation channel, the proteins encounter a membrane-associated enzyme complex termed oligosaccharyltransferase (OST), which catalyzes the transfer of the high mannose oligosaccharide precursor $\mathrm{Glc}_{3} \mathrm{Man}_{9} \mathrm{GlcNAc}_{2}$ from a dolichol diphosphate-linked oligosaccharide donor to the side chain of an asparagine (Asn) residue [16]. The Asn residue appears as part of the consensus sequon Asn-X-Ser/Thr ( $X=$ any amino acid but proline). Following the transfer of the sugar chain by OST, the N-linked carbohydrate molecule undergoes sequential processing by several ER-localized enzymes, resulting in the appearance of a variety of structures, which serve as ligands for the ER protein folding and quality control machinery, a subject which will be discussed later and has been reviewed elsewhere $[15,17,18]$. 
OST is a multi-subunit membrane-protein complex composed of one catalytic subunit (either STT3A or STT3B) and at least six of the following accessory subunits in mammalian cells: Ribophorin 1 and 2 (RPN1, RPN2), DAD1, OST48, TMEM258, OST4, KCP2, DC2/OSTC, and either TUSC3/N33 or IAP/MAGT1 [19]. Each subunit spans the membrane and possesses a significant luminal domain. The OST and Sec61 complexes were found to be tightly bound to each other, probably in order to ensure the $\mathrm{N}$-glycosylation of the consensus sequon as soon as the polypeptide emerges from the translocon to the ER lumen $[20,21]$. The immediate action of OST is crucial for the fate of the glycoproteins. It contributes to the solubility of nascent glycoproteins and directs them to the maturation and quality control machineries by creating recognition tags [22]. OST cryo-electron microscopy structures, which have recently been determined at atomic resolution, reveal its mode of association with the Sec61 translocon and with subunits recognizing the acceptor peptide during its appearance from the translocon [23].

The catalytic subunit STT3A associates with the protein translocation channel and acts in a co-translational fashion. STT3B post-translationally glycosylates specific sequons that are not glycosylated by STT3A [24]. OST48 and DAD1 have major roles in stabilizing both STT3Aand STT3B-containing OST complexes; hence, their depletion results in a severe and global hypoglycosylation phenotype that is directly comparable to that seen upon the depletion of both catalytic STT3 proteins. Similarly, OST4 is required to stabilize STT3 interactions [25]. KCP2 and DC2 are essential for the formation of the major STT3A-containing OST complex and its interaction with the translocon $[26,27]$.

OST complexes containing STT3B require one of two oxidoreductases (MAGT1 or TUSC3) as a subunit that is essential for OST function (Figure 1). MAGT1, also termed IAP, is an ER-localized thioredoxin homologue that associates with the STT3B catalytic subunit and is required for $\mathrm{N}$-glycosylation at sites near cysteine residues. During transfer of the sugar chain, the N-X-S/T sequon must be in an extended strand conformation without a secondary structure. The majority of MAGT1 is present in the oxidized state and forms a transient mixed disulfide bond with a free thiol in the client glycoprotein, delaying intramolecular disulfide bond formation until STT3B glycosylates the acceptor sequon in the nascent polypeptide [28]. MAGT1 was also described as a $\mathrm{Mg}^{2+}$ transporter [29,30]. MAGT1-dependent glycosylation is sensitive to $\mathrm{Mg}^{2+}$ levels, and reduced $\mathrm{Mg}^{2+}$ affects immune cell function via the loss of specific glycoproteins, resulting in suboptimal T-cell activation. In healthy $\mathrm{T}$ and NK cells, MAGT1 is required for N-glycosylation and stabilizing key receptors, which are degraded in its absence. Defects in protein glycosylation and gene expression may lead to immune defects in inherited diseases due to MAGT1 deficiency [31-33]. Mutations in MAGT1 also cause glycosylation defects that lead to intellectual and developmental disability [34] and to X-linked immunodeficiency $[35,36]$.

TUSC3, also called N33, is a homolog of MAGT1, and is enhanced in cases of MAGT1 deficiency as a result of a compensatory mechanism; however, each protein has a different tissue distribution in humans. MAGT1 and TUSC 3 are orthologues of the Saccharomyces cerevisiae Ost 3 and Ost6 proteins. Double knockout of Ost3p and Ost6p resulted in severe defects of N-glycosylation in yeast [37]. The same effect was observed in the absence of both MAGT1 and TUSC3 in mammalian cells [28]. Human MAGT1 and TUSC3 share 73\% identity, possessing several highly conserved structural features. Each has an N-terminal signal peptide followed by a thioredoxin-like domain containing a bi-cysteine motif (CXXC), and a C-terminal domain composed of four membrane-spanning segments. The structures of the luminal domains of Ost 6 and TUSC 3 have been determined, revealing a thioredoxin fold with an active-site CXXC motif that is required for their function [38,39]. TUSC3 possesses a peptide-binding groove adjacent to the active-site cysteine pair, which binds peptides in opposite orientations. This allows TUSC 3 control of sequon recognition and glycosylation efficiency through sequence-specific interactions with polypeptide segments of glycoproteins during co-translational translocation. Similarly to MAGT1, the oxidized form of TUSC 3 was proposed to form transient mixed disulfides with a glycoprotein client, in order to facilitate access of STT3B to the unmodified acceptor 
sequon. TUSC 3 also has oxidoreductase-independent functions in the STT3B-containing OST complex, possibly involving substrate recognition [39]. TUSC3/N33 was initially described as a candidate tumor suppressor based on the location of its gene on the short arm of chromosome 8 , a region frequently lost in various tumors [40]. TUSC 3 knockdown affects the ER structure and stress response and leads to accelerated tumorigenesis in prostate cancer cells under specific conditions [41]. It also enhances the proliferation and migration of ovarian cancer cells in vitro [42]. TUSC 3 interacts with the protein phosphatase 1 (PPPC1A), and similarly to MAGT1, it has been linked to $\mathrm{Mg}^{2+}$ transport, having an important role in learning processes and short- and long-term memory, with its abnormal function leading to mental retardation $[29,43,44]$.

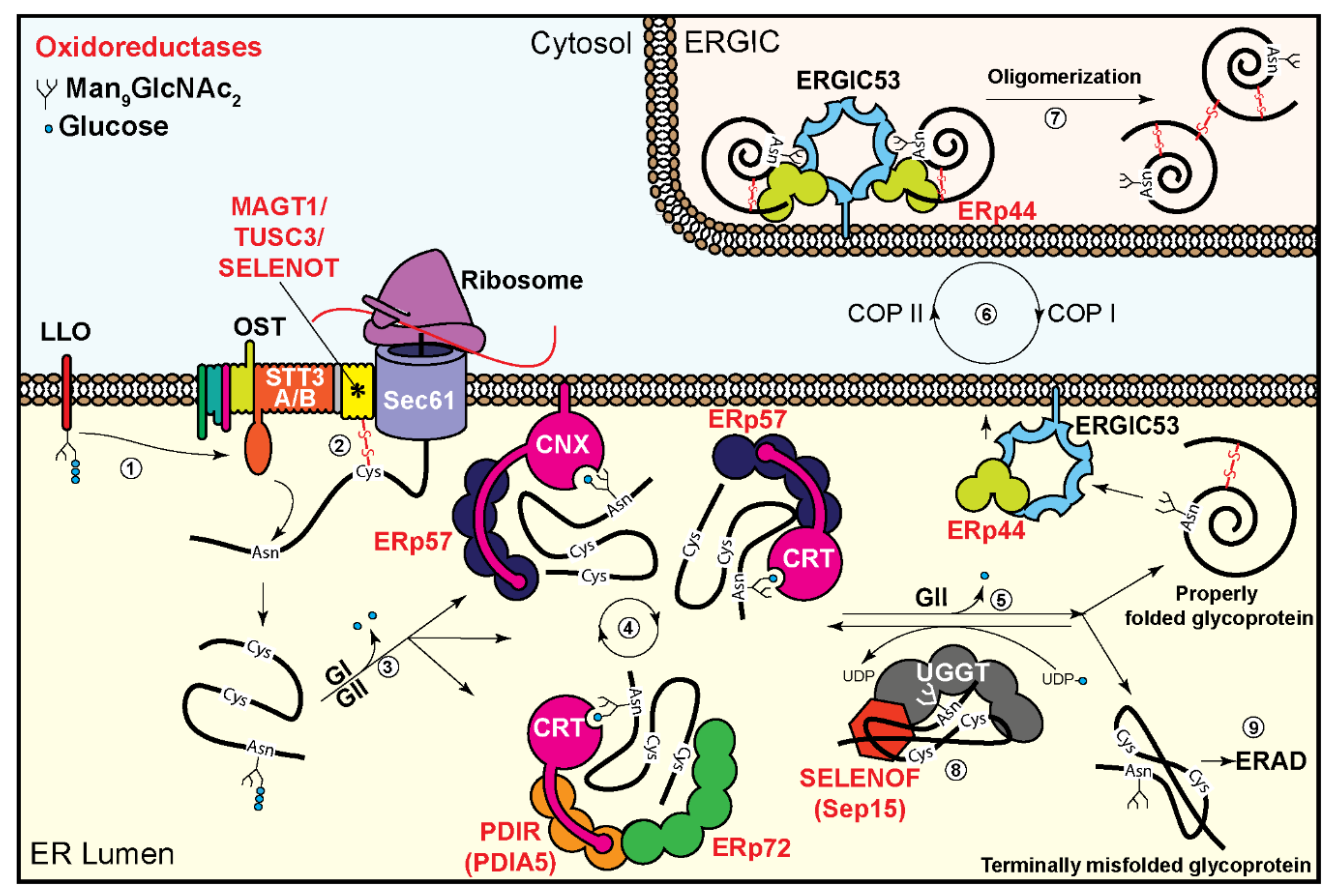

Figure 1. Glycoprotein translocation and folding in the endoplasmic reticulum (ER) in mammalian cells. (1) The oligosaccharide transferase (OST) complex co-translationally transfers the N-glycan precursor $\left(\mathrm{Glc}_{3} \mathrm{Man}_{9} \mathrm{GlcNAc}_{2}\right)$ from the lipid-linked oligosaccharide (LLO) $\left(\mathrm{Gl}_{3} \mathrm{Man}_{9} \mathrm{GlcNAc}_{2}-\mathrm{PP}-\mathrm{Dolichol}\right)$ to an asparagine residue in an $\mathrm{N}$-glycosylation sequon of the glycoprotein during its translocation into the ER. (2) Sugar chain transfer to the glycoprotein is assisted by mixed disulfide bond formation between the glycoprotein and MAGT1 (IAP) or TUSC3 (N33) (in complex with the catalytic OST subunit STT3B), or with selenoprotein T (SELENOT) (in complex with the catalytic OST subunit STT3A). The names of other subunits of the large OST complex are omitted for simplicity. (3) The two terminal glucose residues are removed by Glucosidase I and II (GI and GII), respectively, allowing the glycoprotein to enter folding cycles by the ER chaperones calnexin (CNX) and calreticulin (CRT). (4) The oxidoreductase ERp57 interacts with CNX and CRT, assisting disulfide bond formation. Similar activity is observed by ERp72 indirectly interacting with CRT via PDIR. (5) The removal of the last glucose residue by GII results in the exit of the glycoprotein from the CNX cycle. (6) Properly folded glycoproteins are sent to the Golgi via the ER-Golgi intermediate compartment (ERGIC), mediated by a complex of ERGIC-53 and the oxidoreductase ERp44. (7) The ERGIC53/ERp44 complex is shuttled via COPII vesicles to the ERGIC, where it aids glycoprotein oligomerization. Unassembled subunits are shuttled back to the ER with ERp44 via COPI vesicles. (8) Misfolded glycoproteins are retained in the ER, where they are recognized by UDPGlc:glycoprotein glucosyltransferase (UGGT), with its 4 inactive Trxl domains in a complex with the seleno-oxidoreductase Sep15. UGGT reglucosylates the glycoprotein for re-entry into the CNX folding cycle. (9) Terminally misfolded glycoproteins are targeted to ER-associated degradation (ERAD). Oxidoreductases are marked in red. 
Site-directed mutagenesis analysis revealed that the oxidoreductase CXXC active-site motif of MAGT1 or TUSC3 is essential for the glycosylation of Lassa virus spike glycoprotein, which mediates viral entry into host cells [45]. Catalytic oxidoreductase activity of MAGT1 is also required for Dengue virus propagation, possibly through an effect on viral protein synthesis or folding [46]. These results provide insight into the importance of the OST oxidoreductase subunits for viral interactions with host glycoproteins, and it was suggested that they could emerge as novel antiviral drugs, although potential toxicity should be evaluated.

In addition to MAGT1 and TUSC3, another oxidoreductase, Selenoprotein T, has recently been found to associate with OST complexes containing STT3A [47,48]. Selenoprotein T is a selenocysteine-containing protein with a thioredoxin-like domain containing an active-site CXXU motif. It was proposed that Selenoprotein T might fulfill a function in STT3A-containing OST complexes similar to that of MAGT1 and TUSC3 in STT3B-containing OST (Table 1).

Table 1. A list of oxidoreductases interacting with the glycoprotein processing and folding machinery. Glycoprotein biosynthesis in mammalian cells is separated into different processes, glycosylation, folding, N-glycan processing, ER-Golgi traffic, and ER associated degradation (ERAD). For each process, the specific proteins and their interacting oxidoreductase(s) are shown in the table. Respective thioredoxin-like (Trxl) domains and catalytic or non-catalytic motifs are shown.

\begin{tabular}{|c|c|c|}
\hline Proteins & Interacting Oxidoreductases & Trx-Like Motifs \\
\hline \multicolumn{3}{|c|}{ Glycosylation (OST Complex) } \\
\hline STT3A & SELENOT (SELT) $[47,48]$ & Active: Trxl1-CVSU \\
\hline \multirow{2}{*}{ STT3B } & MAGT1 (IAP) [28-36,45,46] & Active: Trxl1-CVVC \\
\hline & TUSC3 (N33) [28,29,37-45] & Active: Trxl1-CSVC \\
\hline \multicolumn{3}{|c|}{ Protein Folding (Chaperones) } \\
\hline \multirow{3}{*}{$\mathrm{BiP} *$} & PDI (PDA1, P4HB) [49] & Active: Trxl1,4-CGHC; Inactive: $\operatorname{Tr} x 12,3$ \\
\hline & P5 [49] & Active: Trxl1,2-CGHC \\
\hline & ERdj5 (JPDI) $[49,50]$ & $\begin{array}{l}\text { Active: Trxl1-CPPC, Trxl2-CGPC, } \\
\text { Trxl3-CHPC, Trxl4-CSHC }\end{array}$ \\
\hline CNX & ERp57 [51-55] & Active: Trxl1,4-CGHC; Inactive: $\operatorname{Tr} x 12,3$ \\
\hline \multirow{3}{*}{ CRT } & ERp57 [53-55] & \\
\hline & ERp72 [56] & Active: Trxl1,2,5-CGHC; Inactive: Trxl3,4 \\
\hline & PDIR [56] & $\begin{array}{l}\text { Active: Trxl2-CSMC, Trxl3-CGHC, } \\
\text { Trxl4-CPHC; Inactive: Trxl1 }\end{array}$ \\
\hline \multicolumn{3}{|c|}{ N-Glycan Processing (Glucose addition) } \\
\hline \multirow[t]{2}{*}{ UGGT } & & $\begin{array}{l}\text { Inactive: Trxl1 (aa 45-220), Trxl2 (aa 414-656), } \\
\text { Trx13 (aa 667-880), Trxl (aa 275-410 and } \\
897-950)[57,58]\end{array}$ \\
\hline & SELENOF (Sep15) [59] & Active: Trxl1-CGU \\
\hline \multicolumn{3}{|c|}{ N-Glycan Processing (Mannose trimming) } \\
\hline \multirow{2}{*}{ EDEM1 } & P4HB (PDA1, PDI) [60-64] & \\
\hline & TXNDC11 $[63,65]$ & $\begin{array}{l}\text { Active: Trxl1-CELC, Trxl5-CGFC; Inactive: } \\
\text { Trxl2,3,4 }\end{array}$ \\
\hline \multirow{2}{*}{ EDEM2 } & PDI (PDA1, P4HB) [60-64] & \\
\hline & TXNDC11 $[63,65,66]$ & \\
\hline \multirow{2}{*}{ EDEM3 } & TXNDC11 [65] & \\
\hline & ERp46 (TXNDC5) [67] & Active: Trxl1,2,3-CGHC \\
\hline
\end{tabular}


Table 1. Cont.

\begin{tabular}{|c|c|c|}
\hline Proteins & Interacting Oxidoreductases & Trx-Like Motifs \\
\hline \multicolumn{3}{|c|}{ ER-Golgi trafficking and oligomerization } \\
\hline ERGIC-53 & ERp44 (TXNDC4) [68-74] & Active: Trxl1-CRFS; Inactive: Trxl2,3 \\
\hline \multicolumn{3}{|c|}{ ERAD (Retrotranslocation) } \\
\hline \multirow[t]{2}{*}{ OS-9 and SEL1L [75-78] } & ERp90 (TXNDC16) & $\begin{array}{l}\text { Inactive: Trxl1-CX8C, Trx12-CX9C, } \\
\text { Trxl3-CX6C, Trx14,5 }\end{array}$ \\
\hline & ERFAD (FOXRED2) ** & NADPH-dependent reductase \\
\hline EDEM1 & ERdj5 (JPDI) [79-81] & \\
\hline
\end{tabular}

\section{Oxidoreductases Associated with the Glycoprotein Folding Machinery}

Following ER translocation and glycosylation, glycoproteins are subjected to the ER folding and quality control machineries [82]. Proper folding, assisted by molecular chaperones, is critical for achieving the native state and correct protein function. One of the important steps involved in molecular chaperoning is stabilizing the nascent protein using intramolecular or intermolecular disulfide bonds between exposed adjacent cysteine thiol residues [11].

Glycoproteins are subjected to two major folding pathways. One is a general pathway, which also occurs for non-glycosylated proteins, involving the ER HSP70 protein BiP together with PDI and other oxidoreductases. $\mathrm{BiP}$ is the most abundant chaperone in the ER and consists of an N-terminal nucleotide-binding domain (NBD) and a C-terminal substrate-binding domain (SBD), and is a peptide-dependent ATPase that can either increase or decrease the folding rate of protein ligands. The hydrolysis of ATP-bound BiP to ADP is accelerated by ER co-chaperones of the DnaJ family (ERdj proteins), allowing substrate proteins to attain their native conformation and permitting the substrates to assemble with other subunits. The BiP/DnaJ complex also promotes accessibility to other chaperones such as PDI family members that generate and rearrange paired disulfide bonds. In some cases, such as those of P5 and ERdj5, the oxidoreductases interact directly, but non-covalently, with BiP $[49,81]$.

The second pathway is specific for glycoproteins and involves the ER lectin chaperones, calnexin (CNX), an integral membrane protein, and its soluble homologue calreticulin (CRT) [52,83]. These molecular chaperones have two main functional domains, a lectin domain for binding $\mathrm{N}$-linked sugar chains of newly-synthesized glycoproteins, and a proline-rich domain or P-domain, which binds to unfolded protein motifs and is responsible for the interaction with oxidoreductases [52]. One well-studied oxidoreductase, which forms complexes with CNX and CRT, is ERp57 [53]. While the lectin chaperones assist in the proper folding, ERp57 is involved in the disulfide bond formation between proximal cysteines $[54,55]$. Glycoprotein interaction with this system is regulated by sugar chain processing. The initial removal of the two outermost glucose residues from the N-linked oligosaccharide precursor by glucosidase I (GI) and glucosidase II (GII), respectively, creates a monoglucosylated sugar chain that is recognized by CNX or CRT [84]. Dissociation of CNX or CRT from the glycoprotein is elicited by removal of the third mannose-linked glucose by GII, which can be re-added by UDPGlc:glycoprotein glucosyltransferase (UGGT), leading to re-association with the lectin chaperones [52,85]. This "CNX cycle" continues until proper folding of the glycoprotein is achieved, which prevents further recognition by the folding sensor UGGT, allowing exit to the Golgi (Figure 1). If proper folding cannot be achieved in a certain timeframe, the glycoprotein molecules are targeted to ERAD by retrotranslocation to the cytosol and degradation by the ubiquitin-proteasome pathway, as we will discuss later. Whereas the newly-made glycoproteins associate with CNX and CRT in a complex with ERp57, the dissociation of the substrate glycoprotein from ERp57 and from the chaperone lectins follows different kinetics, which are dependent upon its folding state. Misfolded glycoproteins 
quickly dissociate from ERp57, while their association with CNX is prolonged, and the opposite is true for properly folded ones, implicating a role of ERp57 in productive glycoprotein folding [51].

ERp57 contains four thioredoxin-like domains, although only two of them, located at the N-and C-terminal ends, contain CXXC catalytic motifs [52]. Structural analysis showed a strong similarity between ERp57 and another ER localized oxidoreductase, ERp72. ERp72 lacks the binding domain to CNX and CRT. However, another protein with a thioredoxin-like domain, PDIR (also called PDIA5), was found to interact with CRT and with ERp72. The thioredoxin-like domain of PDIR does not contain an active catalytic motif, which suggests that a ternary complex CRT-PDIR-ERp72 may function in glycoprotein folding and disulfide bond formation, with PDIR participating in substrate recognition [56].

Recent findings have also shown the presence of 4 tandem thioredoxin-like domains in the CNX cycle glucosyltransferase, UGGT, suggesting a mechanism for its function as a folding sensor [57]. These domains of UGGT do not carry a catalytic site, and therefore lack a direct role in disulfide bond formation, but expose hydrophobic stretches for recognition of unfolded glycoproteins [58]. UGGT associates with a small selenoprotein, Sep15, also called Selenof [59]. Sep15 contains a catalytically active thioredoxin-like domain, implying that it may have a role in oxidoreductase activity on the glycoprotein substrate. A role of Sep15 in protein quality control is suggested by its upregulation under induced accumulation of misfolded proteins. The exact function of Sep15 is unknown, but its association with UGGT indicates its possible role in either modulating UGGT enzyme activity or assessing the disulfide bonds of the UGGT substrates. Sep15 knockout mice showed increased levels of secreted non-functional immunoglobulins, suggesting that it might function as a quality control gatekeeper for misfolded glycoproteins [59].

A series of membrane-bound lectins, namely ERGIC-53, VIP36, and VIPL, cycle between the ER, the ER to Golgi intermediate compartment (ERGIC), and the Golgi, binding and carrying properly folded glycoproteins that exit the ER. These lectins bind high mannose $\mathrm{N}$-glycans with broad specificity, but with little to no affinity to mannose-trimmed $\mathrm{Man}_{5-6} \mathrm{GlcNAc}_{2}$, which as we will see in the next section are found on misfolded glycoproteins bound for ERAD $[68,86]$. It was shown that ERGIC-53 interacts with the oxidoreductase ERp44 and may act together in assembly of multimeric glycoproteins $[69,70]$ (Figure 1). Many secretory proteins undergo oligomerization via intermolecular disulfide bond formation before exit to the Golgi, with the aid of oxidoreductases. ERp44 is the main oxidoreductase involved in this process. ERp44 was shown to regulate the traffic and the assembly of oligomers of IgM subunits and other secretory proteins [71,72]. It is also responsible for the ER retention of the oxidases ERo1 $\alpha$ and Prx4 [71,73]. ERp44 traffics with its substrates from the ER to the ERGIC compartment via COP II vesicles, and it reduces the substrate thiol groups that will be involved in oligomerization. ERp44 is recycled to its active state by ERo1 $\alpha$ or Prx4 in the ERGIC. The shuttling of ERp44 between the ER and the ERGIC is dependent on the pH difference between these two compartments and is regulated by the presence of $\mathrm{Zn}^{2+}$ in the ERGIC [74]. ERp44 carries a KDEL-like motif for its retrieval to the ER via COP I vesicles.

In the following sections, we will analyze the fate of glycoproteins that do not fold properly and do not traffic to their normal destination.

\section{Involvement of Oxidoreductases in Mannose Trimming of Unfolded Glycoproteins}

One question that remained unanswered for many years was why the cell expends energy to assemble the large precursor $\mathrm{N}$-linked oligosaccharide, only to then catalyze its sequential trimming. The modification of the N-glycan precursor turned out to be intimately linked to the folding, disulfide-bond formation, and complex assembly of glycoproteins. During the CNX folding cycle, N-glycan processing creates a code that reveals the folding status of each glycoprotein molecule, enabling continued folding attempts or targeting of the terminally misfolded glycoprotein for disposal. The code displayed by each structure produced by this trimming and its decoding by lectins has been the subject of research in many studies $[63,66,76,77,87-89]$ and was reviewed in $[15,18,90]$. 
Several mannosidases are involved in the mannose trimming of the N-glycan precursor (Figure 2), which determines the fate of the glycoprotein, signaling whether it should be sent for degradation or exit to the Golgi and proceed to its final destination, as explained below.

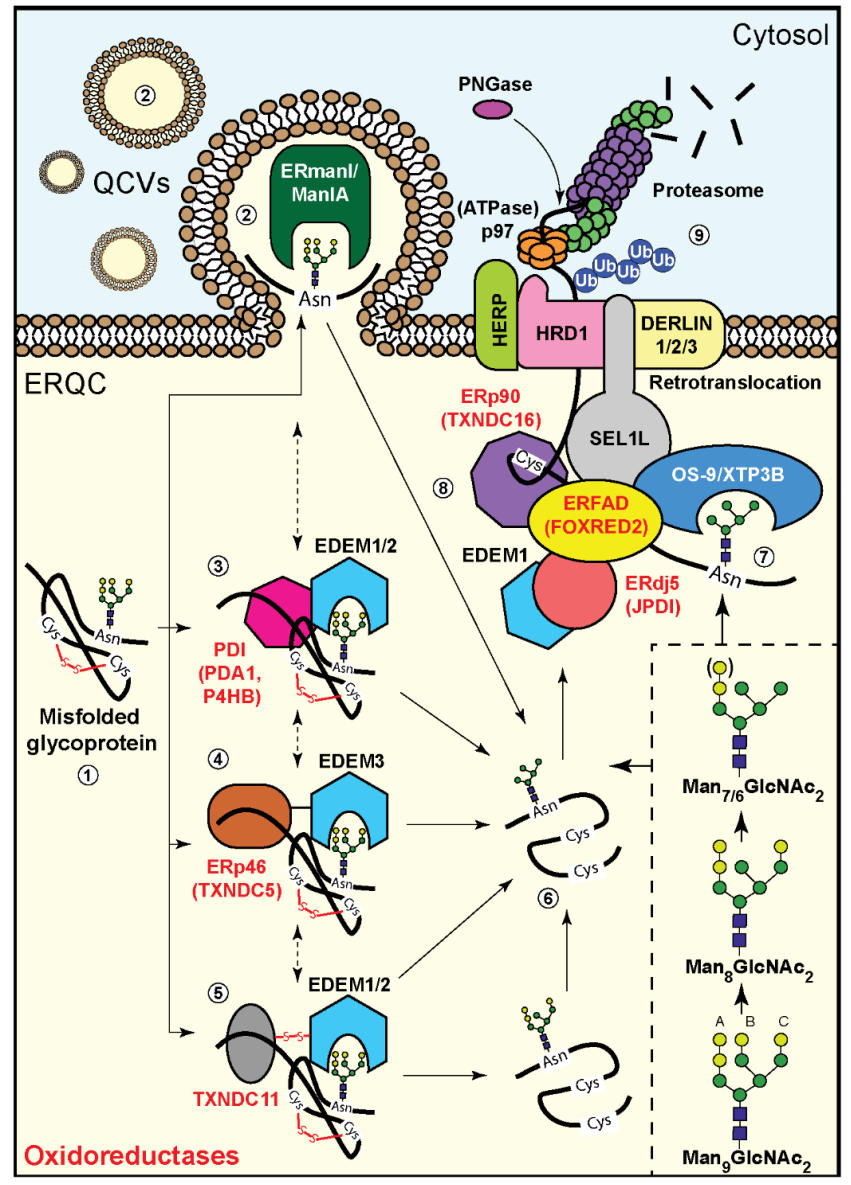

Figure 2. N-Glycan processing and ERAD in mammalian cells. (1) Misfolded glycoproteins carrying $\mathrm{Man}_{9} \mathrm{GlcNAc}_{2}$ are targeted to the ER-derived quality control compartment (ERQC), and their N-glycans are subjected to mannose trimming for their recognition by the ERAD machinery. A scheme on the right depicts mannose trimming of $\alpha 1,2$ mannose residues (light green circles, other mannoses are in dark green, and blue squares are GlcNAc). (2-5) This processing is performed sequentially or in parallel by the $\alpha 1,2$ mannosidases EDEM1-3, ManIA, or ERmanI. (2) ManIA or ERmanI (and possibly the EDEMs) reside in quality control vesicles (QCVs) and interact with the misfolded glycoproteins, likely at vesicle fusion sites. Several oxidoreductases interact with the EDEMs-(3) PDI (PDA1, P4HB) and (5) TXNDC11 associate with EDEM1 and 2, while TXNDC11 and (4) ERp46 (TXNDC5) associate with EDEM3. The associations of the oxidoreductases accelerate the mannose trimming activity of the EDEMs on misfolded glycoproteins, as shown so far for PDI and TXNDC11 with EDEM1/2 and ERp46 with EDEM3. (6,7) Trimming of three or all four $\alpha 1,2$ mannose residues results in glycoprotein molecules carrying $\mathrm{Man}_{5-6} \mathrm{GlcNAc}_{2} \mathrm{~N}$-glycans, which bind to the OS-9/XTP3B lectins that interact with the ERAD complex. (7) OS-9 interacts with SEL1L, an adaptor protein for the E3 ubiquitin ligase HRD1, which associates with the membrane proteins Herp and the Derlins 1-3, among others. (8) OS-9 and SEL1L also interact with a complex of proteins containing Trxl domains, the non-catalytic ERp90 (TXNDC16), and the reductase ERdj5. ERp90 associates with the NAPDH-dependent reductase ERFAD. ERdj5 also interacts with EDEM1. These complexes lead to misfolded glycoprotein reduction, polyubiquitination, and retrotranslocation, with the help of the AAA ATPase p97 on the cytosolic side. (9) Peptide:N-glycosidase (PNGase) removes the N-glycans prior to deubiquitylation and degradation of the misfolded glycoproteins by the proteasomes. For simplicity, several ERAD components, such as p97 adaptors and proteasome shuttling factors, are not depicted. 
$\mathrm{N}$-glycans of misfolded glycoproteins, or of newly-made glycoproteins that fold very slowly, are more extensively trimmed than their properly folded counterparts, and removal of three or four $\alpha 1,2$-linked mannose residues signals their targeting to ERAD. Notably, removal of the terminal mannose residue from the A antenna prevents reglucosylation by UGGT1 and re-entry into the CNX cycle, ending any further protein folding attempts, while the removal of the terminal mannose residues from the B and C antennas allows binding of the N-glycan by the ERAD lectins OS-9 and XTP3-B, promoting degradation [77] (Figure 2). Receptor-mediated trafficking of properly folded glycoproteins out of the ER also relies on N-linked glycans. For example, as mentioned above, the lectin ERGIC-53 (along with VIPL and VIP36) help transfer correctly folded substrates to COPII vesicles for transport out of the ER to the Golgi. The shortened chains, $\mathrm{Man}_{5-6} \mathrm{GlCNAc}_{2}$, are recognized by the ubiquitination machinery-associated OS9 and XTP3-B, but not by the lectins that associate with properly folded glycoproteins trafficking to the Golgi that bind best to $\mathrm{Man}_{8-9} \mathrm{GlcNAc}_{2}$ [68]. Therefore, N-glycan trimming plays a crucial role in releasing substrates from the CNX cycle and targeting them to ERAD when proper folding is not achieved.

The enzyme that was initially implicated in removal of mannose residues, initiating the events that lead to misfolded glycoprotein export to ERAD, is ER mannosidase I (ERManI). ERManI has a preference for trimming the terminal mannose from the B antenna of the N-glycan, but was later found to be capable of removing all $4 \alpha 1$,2-linked mannose residues [87,91]. ERManI was recently found to reside not in the ER, but in specialized quality control vesicles [92]. ERManI is assisted by the mannosidase activities of the ER-degradation-enhancing mannosidase-like proteins (EDEM1, 2, or 3). According to recent studies, ERManI has significant mannosidase activity on free N-glycans and denatured glycoproteins, but has only modest activity on native glycoproteins $[63,93]$. This difference is even more pronounced with EDEMs 1 and 2, which had little or no activity on free glycans, very modest activity on a native glycoprotein, and high activity on a denatured one [63]. In contrast to previous models suggesting general slow mannose trimming, this study revealed that misfolded or unfolded glycoproteins are subject to differentially faster trimming (and thus targeting to ERAD) than well-folded ones.

In addition to its recognition and trimming of N-glycans, EDEM1 can bind to misfolded proteins in a glycan-independent manner [94-96]. Furthermore, EDEM1 upregulation upon UPR induction can target substrate glycoproteins directly to ERAD, bypassing the requirement of mannose trimming to rapidly reduce the protein load in the ER [95].

Recent studies are starting to reveal how the EDEMs recognize unfolded or misfolded proteins, and again oxidoreductases are involved in this recognition. All 3 EDEMs were found to associate with oxidoreductases. EDEM1 and 2 associate with PDI, and also to a greater extent with an ER protein containing five thioredoxin-like domains, TXNDC11, which was implicated in ERAD $[63,65]$ (Figure 2). In Saccharomyces cerevisiae, the association of the EDEM homolog Htm1p (Mnl1p) with PDI is a requirement for its mannosidase activity $[60,64]$. The interaction between Htm1p and PDI includes an intermolecular disulfide bond, which is essential for subsequent formation of a disulfide bond in the mannosidase homology domain of Htm1p, which in turn is in charge of substrate recognition and catalytic activity [97].

For EDEM1 and 2, the association of the oxidoreductases significantly enhanced the in vitro mannosidase activity on a native glycoprotein sample, but not on a denatured one [63]. This suggested that an oxidoreductase-mediated reduction and unfolding was required to expose hydrophobic domains of partially folded or misfolded substrate glycoprotein molecules in the native sample, whereas they were already exposed in the denatured sample. Exposure of the hydrophobic domains of the substrate would significantly enhance its recognition by EDEM1 and 2 [98]. EDEM1 and 2 showed little or no activity on free N-glycans. However, EDEM2 was recently shown to act on free $\mathrm{N}$-glycans by forming a stable disulfide-bonded complex with TXNDC11, converting Man ${ }_{9} \mathrm{GlcNAc}_{2}$ to $\mathrm{Man}_{8} \mathrm{GlcNAc}_{2}$ (isomer B) in vitro [66], a similar preference as ERManI. Nevertheless, it was found that EDEM2 can also remove additional $\alpha 1,2$ mannose residues on glycoproteins [63]. 
TXNDC11 was also reported to be an interactor of EDEM3 [65], although the functional significance of this interaction it is still unknown. A recent study revealed that EDEM3 can associate stably with ERp46 (also called TXNDC5), another ER-resident oxidoreductase. This association was required for the mannosidase activity on misfolded substrate glycoproteins [67]. In vitro degradation of misfolded TCR $\alpha$ was reconstituted only when ERp46 had established a covalent interaction with EDEM3. This interaction, which depended on the redox activity of ERp46, involved formation of a disulfide bond between the cysteine residues of the ERp46 catalytic sites and the EDEM3 $\alpha$-mannosidase domain. ERp46 does not directly change EDEM3 activity, and probably plays a role similar to that of TXNDC11 and PDI for EDEM1 and 2 activity, acting on the glycoprotein substrate [67]. Another study found a thiol-dependent substrate association of EDEM1 with the misfolded $\alpha 1$-antitrypsin variant Null Hong Kong (NHK), through a single Cys residue of the substrate, but this did not involve EDEM1 thiols. A similar thiol dependence was seen for association of the substrate with EDEM2 and 3 [99]. This suggests that it is the associated oxidoreductases, which possibly form mixed disulfides with the glycoprotein substrates.

Glycoproteins entering the Golgi undergo further mannose trimming by one or more of the resident $\alpha 1,2$ mannosidases. There are three "Golgi" $\alpha 1,2$ mannosidases-ManIA, IB, and IC. However, surprisingly, ManIA, which was thought to be a Golgi resident mannosidase, was recently found to localize to quality control vesicles, similarly to ERManI, and to be involved in glycoprotein quality control and targeting to ERAD [100] (Figure 2). It is unknown whether ManIA, IB, or IC activities are dependent on the folding status of the substrate glycoproteins or if any oxidoreductases associate with them, as in the case of the EDEMs. After $\alpha 1,2$ mannose trimming, natively folded glycoprotein molecules are further processed and targeted to their final destination, whereas misfolded glycoproteins are retrieved to the ER for ERAD or are recognized by quality control systems that operate in the Golgi complex and are delivered to lysosomes for degradation [101].

\section{Oxidoreductases and Glycoprotein Targeting to ERAD}

As discussed in the previous section, differential trimming of mannose residues from $\mathrm{N}$-linked glycans determines whether glycoproteins are transported through the Golgi complex, or in the case of irreversibly misfolded glycoproteins, are retained in the ER and degraded by ERAD. This mechanism of protein surveillance is closely linked to redox and $\mathrm{Ca}^{2+}$ homeostasis. $\mathrm{Ca}^{2+}$ is necessary for the function of the major chaperones in the ER, including calnexin, calreticulin, BiP, and some PDIs. Inhibition of $\mathrm{Ca}^{2+}$ uptake into the ER causes ER stress due to inefficient protein folding and accumulation of unfolded or misfolded proteins. Consequently, maintenance of $\mathrm{Ca}^{2+}$ homeostasis is critically important for the functional integrity of the ER [102]. The main regulator of $\mathrm{Ca}^{2+}$ uptake into the ER is the sarco/endoplasmic reticulum calcium pump (SERCA), the activity of which is regulated by redox conditions (reviewed by Roscoe and Sevier in this Special Issue).

As we have seen, ER oxidoreductases are involved in the productive folding of newly synthesized glycoproteins, but they are also implicated in ERAD of misfolded glycoproteins. ERAD requires transport of a misfolded protein through the ER membrane to the cytosol, in a process called retrotranslocation. The mechanism involves recognition and segregation of terminally misfolded proteins from folding intermediates, targeting the former to membrane-bound ubiquitination complexes (the best-studied of which contains the HRD1 ubiquitin ligase), and finally degradation by cytosolic proteasomes (Figure 2). The HRD1 complex was suggested to be recruited by the homocysteine-induced ER protein (Herp) [103-108]. An important role in ERAD is played by p97 (Cdc48 in Saccharomyces cerevisiae), a member of the AAA (ATPase Associated with various cellular Activities) ATPase family. In conjunction with a large number of alternative cofactors and adaptors, p97 couples ATP hydrolysis to segregation of polypeptides from immobile cellular structures, such as protein assemblies, membranes, ribosomes, and chromatin. This often results in proteasomal degradation of the extracted polypeptides, and in ERAD p97 provides (in a complex with cofactors Ufd1 and Np14) force for protein dislocation from the ER membrane to the cytosolic proteasomes [109-113]. P97 is recruited to the site of retrotranslocation 
through association with proteins present in the retrotranslocation complex, including the Derlins 1-3 and HRD1. These proteins each bear a p97 interacting motif, and the interactions with p97 allow the effective capture of substrates emerging from the proposed retrotranslocation channel [114].

There is evidence that the retrotranslocation process entails reduction of disulfide bonds of the substrate protein for unfolding, and several oxidoreductases have been implicated in this reduction and targeting to ERAD [115]. For the substrate recognition step, one non-catalytic member of the PDI-family, ERp90, interacts with misfolded proteins and associates with ERFAD, also known as FOXRED2, an NADPH-dependent reductase flavoprotein. In cells, ERFAD interacts with the ERAD luminal factors OS-9 and ERdj5 and the ER membrane protein SEL1L [78] (Figure 2). For glycoproteins, as explained above, mannose trimming allows recognition and binding to the lectins OS-9 and XTP3-B [76,77]. OS-9 associates with SEL1L, which in turn is in a complex with HRD1, thus targeting the glycoprotein for retrotranslocation [75]. One of the mannosidases involved in the trimming, EDEM1, has been found to associate with the oxidoreductase ERdj5. ERdj5, also known as JPDI (J-domain-containing PDI-like protein), functions as a reductase that reduces disulfides in misfolded ERAD substrates, such as $\alpha 1$-antitrypsin NHK, facilitating their retrotranslocation and degradation [79-81]. Biochemical analyses indicated that two thioredoxin domains that constitute the C-terminal cluster of ERdj5 form the reducing motif that interacts with EDEM1 and reduces disulfide bonds in EDEM1-associated glycoprotein substrates [79,80]. Through its J domain, ERdj5 also associates with BiP; ERdj5 appears to be crucial for ERAD, as ERdj5 knockout causes misfolded protein buildup and ER stress [50]. Nevertheless, the action of ERdj5 does not always lead to ERAD. Association of ERdj5 with the low-density lipoprotein receptor (LDLR) reduced non-native disulfides, allowing isomerization and productive folding [116]. Hence, ERdj5 acts as an ER reductase, both facilitating ERAD of misfolded proteins and catalyzing the folding of proteins, such as LDLR, that form obligatory transient non-native disulfides.

Another reductase that has recently been implicated in ERAD is TXNDC11. TXNDC11 was identified in screens involving gene trap mutagenesis and CRISPR/Cas9-mediated knockout in human haploid cells. It was found to be required for ERAD of various substrates, including unassembled $\mathrm{CD} 3 \delta, \mathrm{TCR} \alpha$, and mutant $\alpha 1$-antitrypsin NHK, but not for NHK-QQQ, a non-glycosylated version [65]. As mentioned before, TXNDC11 interacts with the EDEMs, enabling mannose trimming of their substrates. Therefore, the glycan processing appears to be coupled to the reduction of the disulfide bonds and targeting to retrotranslocation. PDI, which also interacts with EDEM1 and 2 [63], has likewise been implicated in reduction of glycoproteins for ERAD, in the turnover of Hedgehog, and in the degradation of mutant Akita pro-insulin in mammalian cells [61,62]. PDI is also required for ERAD of mutant carboxypeptidase $\mathrm{Y}(\mathrm{CPY})$ in yeast [117].

\section{Concluding Remarks}

Studies in recent years have uncovered a tight cooperation between oxidoreductases and the glycoprotein processing machineries. This teamwork goes beyond disulfide bonding of cysteines in the proximity of sugar chains. Oxidoreductases interact with components of the machineries in charge of glycan addition, glycan processing, glycoprotein quality control, and ERAD targeting. They are involved in disulfide bond formation, the recognition of misfolded glycoproteins, and in accelerating the action of mannosidases that target the misfolded glycoproteins to ERAD). Oxidoreductases are also involved in disulfide reduction for isomerization of properly folded glycoproteins or before retrotranslocation and ERAD of misfolded glycoproteins. Nevertheless, we are only at the beginning of the discovery process, as the role of most of the multiple ER oxidoreductases or of their association with glycoprotein-specific machinery is still unknown.

Some of the questions that remain open are whether there are oxidoreductases acting on glycoproteins in post-ER compartments. Are there oxidoreductases functionally associated with the "Golgi" mannosidases IA, IB, and IC? Are other reductases involved in ERAD? What is the detailed mechanism of misfolded protein domain recognition by the oxidoreductases and is there an advantage when it involves mixed disulfide bonds? What are the mechanistic changes upon ER 
stress and oxidative stress? During oxidative stress, one could envisage a change in the balance of oxidases, favoring expression of those that consume peroxides. Upon ER stress, one could expect increased expression of both oxidoreductases that accelerate disulfide bond formation and reductases that increase disulfide bond reduction and facilitate ERAD to reduce ER protein load.

Funding: Research related to this article was supported by grants (1593/16 and 2577/20) from the Israel Science Foundation.

Conflicts of Interest: The authors declare no conflict of interest.

\section{References}

1. Bošnjak, I.; Bojović, V.; Šegvić-Bubić, T.; Bielen, A. Occurrence of protein disulfide bonds in different domains of life: A comparison of proteins from the Protein Data Bank. Protein. Eng. Des. Sel. 2014, 27, 65-72. [CrossRef] [PubMed]

2. Robinson, P.J.; Bulleid, N.J. Mechanisms of Disulfide Bond Formation in Nascent Polypeptides Entering the Secretory Pathway. Cells 2020, 9, 1994. [CrossRef] [PubMed]

3. Guerra, C.; Molinari, M. Thioredoxin-Related Transmembrane Proteins: TMX1 and Little Brothers TMX2, TMX3, TMX4 and TMX5. Cells 2020, 9, 2000. [CrossRef]

4. Araki, K.; Inaba, K. Structure, mechanism, and evolution of Ero1 family enzymes. Antioxid. Redox. Signal. 2012, 16, 790-799. [CrossRef]

5. Gross, E.; Sevier, C.S.; Heldman, N.; Vitu, E.; Bentzur, M.; Kaiser, C.A.; Thorpe, C.; Fass, D. Generating disulfides enzymatically: Reaction products and electron acceptors of the endoplasmic reticulum thiol oxidase Ero1p. Proc. Natl. Acad. Sci. USA 2006, 103, 299-304. [CrossRef]

6. Nguyen, V.D.; Saaranen, M.J.; Karala, A.R.; Lappi, A.K.; Wang, L.; Raykhel, I.B.; Alanen, H.I.; Salo, K.E.; Wang, C.C.; Ruddock, L.W. Two endoplasmic reticulum PDI peroxidases increase the efficiency of the use of peroxide during disulfide bond formation. J. Mol. Biol. 2011, 406, 503-515. [CrossRef] [PubMed]

7. Tavender, T.J.; Springate, J.J.; Bulleid, N.J. Recycling of peroxiredoxin IV provides a novel pathway for disulphide formation in the endoplasmic reticulum. EMBO J. 2010, 29, 4185-4197. [CrossRef]

8. Zito, E.; Melo, E.P.; Yang, Y.; Wahlander, Å.; Neubert, T.A.; Ron, D. Oxidative protein folding by an endoplasmic reticulum-localized peroxiredoxin. Mol. Cell 2010, 40, 787-797. [CrossRef]

9. Benham, A.M. The protein disulfide isomerase family: Key players in health and disease. Antioxid. Redox. Signal. 2012, 16, 781-789. [CrossRef]

10. Fass, D.; Thorpe, C. Chemistry and Enzymology of Disulfide Cross-Linking in Proteins. Chem. Rev. 2018, 118, 1169-1198. [CrossRef]

11. Hudson, D.A.; Gannon, S.A.; Thorpe, C. Oxidative protein folding: From thiol-disulfide exchange reactions to the redox poise of the endoplasmic reticulum. Free Radic. Biol. Med. 2015, 80, 171-182. [CrossRef] [PubMed]

12. Arnér, E.S. Selenoproteins-What unique properties can arise with selenocysteine in place of cysteine? Exp. Cell Res. 2010, 316, 1296-1303. [CrossRef] [PubMed]

13. Pitts, M.W.; Hoffmann, P.R. Endoplasmic reticulum-resident selenoproteins as regulators of calcium signaling and homeostasis. Cell Calcium 2018, 70, 76-86. [CrossRef]

14. Lu, J.; Holmgren, A. Selenoproteins. J. Biol. Chem. 2009, 284, 723-727. [CrossRef] [PubMed]

15. Shenkman, M.; Lederkremer, G.Z. Compartmentalization and Selective Tagging for Disposal of Misfolded Glycoproteins. Trends Biochem. Sci. 2019, 44, 827-836. [CrossRef] [PubMed]

16. Kornfeld, R.; Kornfeld, S. Assembly of asparagine-linked oligosaccharides. Annu. Rev. Biochem. 1985, 54, 631-664. [CrossRef] [PubMed]

17. Aebi, M.; Bernasconi, R.; Clerc, S.; Molinari, M. N-glycan structures: Recognition and processing in the ER. Trends Biochem. Sci. 2010, 35, 74-82. [CrossRef] [PubMed]

18. Tannous, A.; Pisoni, G.B.; Hebert, D.N.; Molinari, M. N-linked sugar-regulated protein folding and quality control in the ER. Semin. Cell Dev. Biol. 2015, 41, 79-89. [CrossRef]

19. Mohanty, S.; Chaudhary, B.P.; Zoetewey, D. Structural Insight into the Mechanism of N-Linked Glycosylation by Oligosaccharyltransferase. Biomolecules 2020, 10, 624. [CrossRef] 
20. Mohorko, E.; Glockshuber, R.; Aebi, M. Oligosaccharyltransferase: The central enzyme of N-linked protein glycosylation. J. Inherit. Metab. Dis. 2011, 34, 869-878. [CrossRef]

21. Pfeffer, S.; Dudek, J.; Gogala, M.; Schorr, S.; Linxweiler, J.; Lang, S.; Becker, T.; Beckmann, R.; Zimmermann, R.; Förster, F. Structure of the mammalian oligosaccharyl-transferase complex in the native ER protein translocon. Nat. Commun. 2014, 5, 3072. [CrossRef] [PubMed]

22. Braakman, I.; Bulleid, N.J. Protein folding and modification in the mammalian endoplasmic reticulum. Annu. Rev. Biochem. 2011, 80, 71-99. [CrossRef] [PubMed]

23. Bai, L.; Wang, T.; Zhao, G.; Kovach, A.; Li, H. The atomic structure of a eukaryotic oligosaccharyltransferase complex. Nature 2018, 555, 328-333. [CrossRef] [PubMed]

24. Ruiz-Canada, C.; Kelleher, D.J.; Gilmore, R. Cotranslational and posttranslational N-glycosylation of polypeptides by distinct mammalian OST isoforms. Cell 2009, 136, 272-283. [CrossRef]

25. Dumax-Vorzet, A.; Roboti, P.; High, S. OST4 is a subunit of the mammalian oligosaccharyltransferase required for efficient N-glycosylation. J. Cell Sci. 2013, 126 Pt 12, 2595-2606. [CrossRef]

26. Shrimal, S.; Cherepanova, N.A.; Gilmore, R. DC2 and KCP2 mediate the interaction between the oligosaccharyltransferase and the ER translocon. J. Cell Biol. 2017, 216, 3625-3638. [CrossRef] [PubMed]

27. Roboti, P.; High, S. The oligosaccharyltransferase subunits OST48, DAD1 and KCP2 function as ubiquitous and selective modulators of mammalian N-glycosylation. J. Cell Sci. 2012, 125 Pt 14, 3474-3484. [CrossRef]

28. Cherepanova, N.A.; Shrimal, S.; Gilmore, R. Oxidoreductase activity is necessary for N-glycosylation of cysteine-proximal acceptor sites in glycoproteins. J. Cell Biol. 2014, 206, 525-539. [CrossRef]

29. Zhou, H.; Clapham, D.E. Mammalian MagT1 and TUSC3 are required for cellular magnesium uptake and vertebrate embryonic development. Proc. Natl. Acad. Sci. USA 2009, 106, 15750-15755. [CrossRef]

30. Goytain, A.; Quamme, G.A. Identification and characterization of a novel mammalian $\mathrm{Mg} 2+$ transporter with channel-like properties. BMC Genom. 2005, 6, 48. [CrossRef]

31. Matsuda-Lennikov, M.; Biancalana, M.; Zou, J.; Ravell, J.C.; Zheng, L.; Kanellopoulou, C.; Jiang, P.; Notarangelo, G.; Jing, H.; Masutani, E.; et al. Magnesium transporter 1 (MAGT1) deficiency causes selective defects in N-linked glycosylation and expression of immune-response genes. J. Biol. Chem. 2019, 294, 13638-13656. [CrossRef] [PubMed]

32. Chaigne-Delalande, B.; Li, F.Y.; O'Connor, G.M.; Lukacs, M.J.; Jiang, P.; Zheng, L.; Shatzer, A.; Biancalana, M.; Pittaluga, S.; Matthews, H.F.; et al. $\mathrm{Mg}^{2+}$ regulates cytotoxic functions of NK and CD8 T cells in chronic EBV infection through NKG2D. Science 2013, 341, 186-191. [CrossRef] [PubMed]

33. Li, F.Y.; Lenardo, M.J.; Chaigne-Delalande, B. Loss of MAGT1 abrogates the $\mathrm{Mg}^{2+}$ flux required for T cell signaling and leads to a novel human primary immunodeficiency. Magnes. Res. 2011, 24, S109-S114. [CrossRef] [PubMed]

34. Blommaert, E.; Péanne, R.; Cherepanova, N.A.; Rymen, D.; Staels, F.; Jaeken, J.; Race, V.; Keldermans, L.; Souche, E.; Corveleyn, A.; et al. Mutations in MAGT1 lead to a glycosylation disorder with a variable phenotype. Proc. Natl. Acad. Sci. USA 2019, 116, 9865-9870. [CrossRef] [PubMed]

35. Li, F.Y.; Chaigne-Delalande, B.; Kanellopoulou, C.; Davis, J.C.; Matthews, H.F.; Douek, D.C.; Cohen, J.I.; Uzel, G.; Su, H.C.; Lenardo, M.J. Second messenger role for $\mathrm{Mg}^{2+}$ revealed by human T-cell immunodeficiency. Nature 2011, 475, 471-476. [CrossRef]

36. Ravell, J.C.; Chauvin, S.D.; He, T.; Lenardo, M. An Update on XMEN Disease. J. Clin. Immunol. 2020, 40, 671-681. [CrossRef]

37. Schwarz, M.; Knauer, R.; Lehle, L. Yeast oligosaccharyltransferase consists of two functionally distinct sub-complexes, specified by either the Ost3p or Ost6p subunit. FEBS Lett. 2005, 579, 6564-6568. [CrossRef]

38. Schulz, B.L.; Stirnimann, C.U.; Grimshaw, J.P.; Brozzo, M.S.; Fritsch, F.; Mohorko, E.; Capitani, G.; Glockshuber, R.; Grütter, M.G.; Aebi, M. Oxidoreductase activity of oligosaccharyltransferase subunits Ost3p and Ost6p defines site-specific glycosylation efficiency. Proc. Natl. Acad. Sci. USA 2009, 106, 11061-11066. [CrossRef]

39. Mohorko, E.; Owen, R.L.; Malojčić, G.; Brozzo, M.S.; Aebi, M.; Glockshuber, R. Structural basis of substrate specificity of human oligosaccharyl transferase subunit N33/Tusc3 and its role in regulating protein N-glycosylation. Structure 2014, 22, 590-601. [CrossRef]

40. MacGrogan, D.; Levy, A.; Bova, G.S.; Isaacs, W.B.; Bookstein, R. Structure and methylation-associated silencing of a gene within a homozygously deleted region of human chromosome band 8p22. Genomics 1996, 35, 55-65. [CrossRef] 
41. Horak, P.; Tomasich, E.; Vaňhara, P.; Kratochvílová, K.; Anees, M.; Marhold, M.; Lemberger, C.E.; Gerschpacher, M.; Horvat, R.; Sibilia, M.; et al. TUSC3 loss alters the ER stress response and accelerates prostate cancer growth in vivo. Sci. Rep. 2014, 4, 3739. [CrossRef] [PubMed]

42. Vaňhara, P.; Horak, P.; Pils, D.; Anees, M.; Petz, M.; Gregor, W.; Zeillinger, R.; Krainer, M. Loss of the oligosaccharyl transferase subunit TUSC3 promotes proliferation and migration of ovarian cancer cells. Int. J. Oncol. 2013, 42, 1383-1389. [CrossRef] [PubMed]

43. Garshasbi, M.; Hadavi, V.; Habibi, H.; Kahrizi, K.; Kariminejad, R.; Behjati, F.; Tzschach, A.; Najmabadi, H.; Ropers, H.H.; Kuss, A.W. A defect in the TUSC3 gene is associated with autosomal recessive mental retardation. Am. J. Hum. Genet. 2008, 82, 1158-1164. [CrossRef] [PubMed]

44. Slutsky, I.; Abumaria, N.; Wu, L.J.; Huang, C.; Zhang, L.; Li, B.; Zhao, X.; Govindarajan, A.; Zhao, M.G.; Zhuo, M.; et al. Enhancement of learning and memory by elevating brain magnesium. Neuron 2010, 65, 165-177. [CrossRef]

45. Zhu, S.; Wan, W.; Zhang, Y.; Shang, W.; Pan, X.; Zhang, L.K.; Xiao, G. Comprehensive Interactome Analysis Reveals that STT3B Is Required for N-Glycosylation of Lassa Virus Glycoprotein. J. Virol. 2019, 93. [CrossRef]

46. Lin, L.D.; Cherepanova, N.A.; Bozzacco, L.; MacDonald, M.R.; Gilmore, R.; Tai, A.W. Dengue Virus Hijacks a Noncanonical Oxidoreductase Function of a Cellular Oligosaccharyltransferase Complex. mBio 2017, 8. [CrossRef]

47. Hamieh, A.; Cartier, D.; Abid, H.; Calas, A.; Burel, C.; Bucharles, C.; Jehan, C.; Grumolato, L.; Landry, M.; Lerouge, P.; et al. Selenoprotein $\mathrm{T}$ is a novel OST subunit that regulates UPR signaling and hormone secretion. EMBO Rep. 2017, 18, 1935-1946. [CrossRef]

48. Pothion, H.; Jehan, C.; Tostivint, H.; Cartier, D.; Bucharles, C.; Falluel-Morel, A.; Boukhzar, L.; Anouar, Y.; Lihrmann, I. Selenoprotein T: An Essential Oxidoreductase Serving as a Guardian of Endoplasmic Reticulum Homeostasis. Antioxid. Redox. Signal 2020. [CrossRef]

49. Jessop, C.E.; Watkins, R.H.; Simmons, J.J.; Tasab, M.; Bulleid, N.J.J. Protein disulphide isomerase family members show distinct substrate specificity: P5 is targeted to BiP client proteins. J. Cell Sci. 2009, 122 Pt 23, 4287-4295. [CrossRef]

50. Hosoda, A.; Tokuda, M.; Akai, R.; Kohno, K.; Iwawaki, T. Positive contribution of ERdj5/JPDI to endoplasmic reticulum protein quality control in the salivary gland. Biochem J. 2009, 425, 117-125. [CrossRef]

51. Frenkel, Z.; Shenkman, M.; Kondratyev, M.; Lederkremer, G.Z. Separate roles and different routing of calnexin and ERp57 in endoplasmic reticulum quality control revealed by interactions with asialoglycoprotein receptor chains. Mol. Biol. Cell 2004, 15, 2133-2142. [CrossRef] [PubMed]

52. Kozlov, G.; Gehring, K. Calnexin cycle-Structural features of the ER chaperone system. FEBS J. 2020. [CrossRef] [PubMed]

53. Zapun, A.; Darby, N.J.; Tessier, D.C.; Michalak, M.; Bergeron, J.J.; Thomas, D.Y. Enhanced catalysis of ribonuclease B folding by the interaction of calnexin or calreticulin with ERp57. J. Biol. Chem. 1998, 273, 6009-6012. [CrossRef] [PubMed]

54. Frickel, E.M.; Frei, P.; Bouvier, M.; Stafford, W.F.; Helenius, A.; Glockshuber, R.; Ellgaard, L. ERp57 is a multifunctional thiol-disulfide oxidoreductase. J. Biol. Chem. 2004, 279, 18277-18287. [CrossRef] [PubMed]

55. Oliver, J.D.; van der Wal, F.J.; Bulleid, N.J.; High, S. Interaction of the thiol-dependent reductase ERp57 with nascent glycoproteins. Science 1997, 275, 86-88. [CrossRef] [PubMed]

56. Vinaik, R.; Kozlov, G.; Gehring, K. Structure of the non-catalytic domain of the protein disulfide isomerase-related protein (PDIR) reveals function in protein binding. PLoS ONE 2013, 8, e62021. [CrossRef]

57. Roversi, P.; Marti, L.; Caputo, A.T.; Alonzi, D.S.; Hill, J.C.; Dent, K.C.; Kumar, A.; Levasseur, M.D.; Lia, A.; Waksman, T; et al. Interdomain conformational flexibility underpins the activity of UGGT, the eukaryotic glycoprotein secretion checkpoint. Proc. Natl. Acad. Sci. USA 2017, 114, 8544-8549. [CrossRef]

58. Satoh, T.; Song, C.; Zhu, T.; Toshimori, T.; Murata, K.; Hayashi, Y.; Kamikubo, H.; Uchihashi, T.; Kato, K. Visualisation of a flexible modular structure of the ER folding-sensor enzyme UGGT. Sci. Rep. 2017, 7, 12142. [CrossRef]

59. Yim, S.H.; Everley, R.A.; Schildberg, F.A.; Lee, S.G.; Orsi, A.; Barbati, Z.R.; Karatepe, K.; Fomenko, D.E.; Tsuji, P.A.; Luo, H.R.; et al. Role of Selenof as a Gatekeeper of Secreted Disulfide-Rich Glycoproteins. Cell Rep. 2018, 23, 1387-1398. [CrossRef] 
60. Liu, Y.C.; Fujimori, D.G.; Weissman, J.S. Htm1p-Pdi1p is a folding-sensitive mannosidase that marks N-glycoproteins for ER-associated protein degradation. Proc. Natl. Acad. Sci. USA 2016, 113, E4015-E4024. [CrossRef]

61. Chen, X.; Tukachinsky, H.; Huang, C.H.; Jao, C.; Chu, Y.R.; Tang, H.Y.; Mueller, B.; Schulman, S.; Rapoport, T.A.; Salic, A. Processing and turnover of the Hedgehog protein in the endoplasmic reticulum. J. Cell Biol. 2011, 192, 825-838. [CrossRef]

62. He, K.; Cunningham, C.N.; Manickam, N.; Liu, M.; Arvan, P.; Tsai, B. PDI reductase acts on Akita mutant proinsulin to initiate retrotranslocation along the Hrd1/Sel1L-p97 axis. Mol. Biol. Cell 2015, 26, 3413-3423. [CrossRef]

63. Shenkman, M.; Ron, E.; Yehuda, R.; Benyair, R.; Khalaila, I.; Lederkremer, G.Z. Mannosidase activity of EDEM1 and EDEM2 depends on an unfolded state of their glycoprotein substrates. Commun. Biol. 2018, 1, 172. [CrossRef] [PubMed]

64. Pfeiffer, A.; Stephanowitz, H.; Krause, E.; Volkwein, C.; Hirsch, C.; Jarosch, E.; Sommer, T. A Complex of Htm1 and the Oxidoreductase Pdi1 Accelerates Degradation of Misfolded Glycoproteins. J. Biol. Chem. 2016, 291, 12195-12207. [CrossRef] [PubMed]

65. Timms, R.T.; Menzies, S.A.; Tchasovnikarova, I.A.; Christensen, L.C.; Williamson, J.C.; Antrobus, R.; Dougan, G.; Ellgaard, L.; Lehner, P.J. Genetic dissection of mammalian ERAD through comparative haploid and CRISPR forward genetic screens. Nat. Commun. 2016, 7, 11786. [CrossRef] [PubMed]

66. George, G.; Ninagawa, S.; Yagi, H.; Saito, T.; Ishikawa, T.; Sakuma, T.; Yamamoto, T.; Imami, K.; Ishihama, Y.; Kato, K.; et al. EDEM2 stably disulfide-bonded to TXNDC11 catalyzes the first mannose trimming step in mammalian glycoprotein ERAD. eLife 2020, 9, e53455. [CrossRef] [PubMed]

67. Yu, S.; Ito, S.; Wada, I.; Hosokawa, N. ER-resident protein 46 (ERp46) triggers the mannose-trimming activity of ER degradation-enhancing $\alpha$-mannosidase-like protein 3 (EDEM3). J. Biol. Chem. 2018, 293, 10663-10674. [CrossRef] [PubMed]

68. Kamiya, Y.; Kamiya, D.; Yamamoto, K.; Nyfeler, B.; Hauri, H.P.; Kato, K. Molecular basis of sugar recognition by the human L-type lectins ERGIC-53, VIPL, and VIP36. J. Biol. Chem. 2008, 283, 1857-1861. [CrossRef]

69. Anelli, T.; Ceppi, S.; Bergamelli, L.; Cortini, M.; Masciarelli, S.; Valetti, C.; Sitia, R. Sequential steps and checkpoints in the early exocytic compartment during secretory IgM biogenesis. EMBO J. 2007, 26, 4177-4188. [CrossRef]

70. Cortini, M.; Sitia, R. ERp44 and ERGIC-53 synergize in coupling efficiency and fidelity of IgM polymerization and secretion. Traffic 2010, 11, 651-659. [CrossRef]

71. Anelli, T.; Alessio, M.; Bachi, A.; Bergamelli, L.; Bertoli, G.; Camerini, S.; Mezghrani, A.; Ruffato, E.; Simmen, T.; Sitia, R. Thiol-mediated protein retention in the endoplasmic reticulum: The role of ERp44. EMBO J. 2003, 22, 5015-5022. [CrossRef] [PubMed]

72. Mariappan, M.; Radhakrishnan, K.; Dierks, T.; Schmidt, B.; von Figura, K. ERp44 mediates a thiol-independent retention of formylglycine-generating enzyme in the endoplasmic reticulum. J. Biol. Chem. 2008, 283, 6375-6383. [CrossRef] [PubMed]

73. Kakihana, T.; Araki, K.; Vavassori, S.; Iemura, S.; Cortini, M.; Fagioli, C.; Natsume, T.; Sitia, R.; Nagata, K. Dynamic regulation of Ero1 $\alpha$ and peroxiredoxin 4 localization in the secretory pathway. J. Biol. Chem. 2013, 288, 29586-29594. [CrossRef] [PubMed]

74. Watanabe, S.; Amagai, Y.; Sannino, S.; Tempio, T.; Anelli, T.; Harayama, M.; Masui, S.; Sorrentino, I.; Yamada, M.; Sitia, R.; et al. Zinc regulates ERp44-dependent protein quality control in the early secretory pathway. Nat. Commun. 2019, 10, 603. [CrossRef] [PubMed]

75. Christianson, J.C.; Shaler, T.A.; Tyler, R.E.; Kopito, R.R. OS-9 and GRP94 deliver mutant alpha1-antitrypsin to the Hrd1-SEL1L ubiquitin ligase complex for ERAD. Nat. Cell Biol. 2008, 10, 272-282. [CrossRef]

76. Groisman, B.; Shenkman, M.; Ron, E.; Lederkremer, G.Z. Mannose trimming is required for delivery of a glycoprotein from EDEM1 to XTP3-B and to late endoplasmic reticulum-associated degradation steps. J. Biol. Chem. 2011, 286, 1292-1300. [CrossRef]

77. Hosokawa, N.; Kamiya, Y.; Kamiya, D.; Kato, K.; Nagata, K. Human OS-9, a lectin required for glycoprotein endoplasmic reticulum-associated degradation, recognizes mannose-trimmed N-glycans. J. Biol. Chem. 2009, 284, 17061-17068. [CrossRef]

78. Riemer, J.; Hansen, H.G.; Appenzeller-Herzog, C.; Johansson, L.; Ellgaard, L. Identification of the PDI-family member ERp90 as an interaction partner of ERFAD. PLoS ONE 2011, 6, e17037. [CrossRef] 
79. Hagiwara, M.; Maegawa, K.; Suzuki, M.; Ushioda, R.; Araki, K.; Matsumoto, Y.; Hoseki, J.; Nagata, K.; Inaba, K. Structural basis of an ERAD pathway mediated by the ER-resident protein disulfide reductase ERdj5. Mol. Cell 2011, 41, 432-444. [CrossRef]

80. Maegawa, K.I.; Watanabe, S.; Noi, K.; Okumura, M.; Amagai, Y.; Inoue, M.; Ushioda, R.; Nagata, K.; Ogura, T.; Inaba, K. The Highly Dynamic Nature of ERdj5 Is Key to Efficient Elimination of Aberrant Protein Oligomers through ER-Associated Degradation. Structure 2017, 25, 846-857.e4. [CrossRef]

81. Ushioda, R.; Hoseki, J.; Araki, K.; Jansen, G.; Thomas, D.Y.; Nagata, K. ERdj5 is required as a disulfide reductase for degradation of misfolded proteins in the ER. Science 2008, 321, 569-572. [CrossRef] [PubMed]

82. Ellgaard, L.; McCaul, N.; Chatsisvili, A.; Braakman, I. Co- and Post-Translational Protein Folding in the ER. Traffic 2016, 17, 615-638. [CrossRef] [PubMed]

83. Rutkevich, L.A.; Williams, D.B. Participation of lectin chaperones and thiol oxidoreductases in protein folding within the endoplasmic reticulum. Curr. Opin. Cell Biol. 2011, 23, 157-166. [CrossRef] [PubMed]

84. Benyair, R.; Ron, E.; Lederkremer, G.Z. Protein quality control, retention, and degradation at the endoplasmic reticulum. Int. Rev. Cell Mol. Biol. 2011, 292, 197-280. [PubMed]

85. Caramelo, J.J.; Parodi, A.J. A sweet code for glycoprotein folding. FEBS Lett. 2015, 589, 3379-3387. [CrossRef]

86. Lederkremer, G.Z. Glycoprotein folding, quality control and ER-associated degradation. Curr. Opin. Struct. Biol. 2009, 19, 515-523. [CrossRef]

87. Avezov, E.; Frenkel, Z.; Ehrlich, M.; Herscovics, A.; Lederkremer, G.Z. Endoplasmic reticulum (ER) mannosidase I is compartmentalized and required for N-glycan trimming to Man5-6GlcNAc2 in glycoprotein ER-associated degradation. Mol. Biol. Cell 2008, 19, 216-225. [CrossRef]

88. Frenkel, Z.; Gregory, W.; Kornfeld, S.; Lederkremer, G.Z. Endoplasmic reticulum-associated degradation of mammalian glycoproteins involves sugar chain trimming to Man6-5GlcNAc2. J. Biol. Chem. 2003, 278, 34119-34124. [CrossRef]

89. Hosokawa, N.; Tremblay, L.O.; Sleno, B.; Kamiya, Y.; Wada, I.; Nagata, K.; Kato, K.; Herscovics, A. EDEM1 accelerates the trimming of alpha1,2-linked mannose on the C branch of N-glycans. Glycobiology 2010, 20, 567-575. [CrossRef]

90. Benyair, R.; Ogen-Shtern, N.; Lederkremer, G.Z. Glycan regulation of ER-associated degradation through compartmentalization. Semin. Cell Dev. Biol. 2015, 41, 99-109. [CrossRef]

91. Herscovics, A.; Romero, P.A.; Tremblay, L.O. The specificity of the yeast and human class I ER alpha 1,2-mannosidases involved in ER quality control is not as strict previously reported. Glycobiology 2002, 12, 14G-15G. [PubMed]

92. Benyair, R.; Ogen-Shtern, N.; Mazkereth, N.; Shai, B.; Ehrlich, M.; Lederkremer, G.Z. Mammalian ER mannosidase I resides in quality control vesicles, where it encounters its glycoprotein substrates. Mol. Biol. Cell 2015, 26, 172-184. [CrossRef] [PubMed]

93. Aikawa, J.; Matsuo, I.; Ito, Y. In vitro mannose trimming property of human ER alpha-1,2 mannosidase I. Glycocon. J. 2012, 29, 35-45. [CrossRef] [PubMed]

94. Marin, M.B.; Ghenea, S.; Spiridon, L.N.; Chiritoiu, G.N.; Petrescu, A.J.; Petrescu, S.M. Tyrosinase degradation is prevented when EDEM1 lacks the intrinsically disordered region. PLoS ONE 2012, 7, e42998. [CrossRef]

95. Ron, E.; Shenkman, M.; Groisman, B.; Izenshtein, Y.; Leitman, J.; Lederkremer, G.Z. Bypass of glycan-dependent glycoprotein delivery to ERAD by up-regulated EDEM1. Mol. Biol. Cell 2011, 22, 3945-3954. [CrossRef]

96. Shenkman, M.; Groisman, B.; Ron, E.; Avezov, E.; Hendershot, L.M.; Lederkremer, G.Z. A Shared Endoplasmic Reticulum-associated Degradation Pathway Involving the EDEM1 Protein for Glycosylated and Nonglycosylated Proteins. J. Biol. Chem. 2013, 288, 2167-2178. [CrossRef]

97. Sakoh-Nakatogawa, M.; Nishikawa, S.; Endo, T. Roles of protein-disulfide isomerase-mediated disulfide bond formation of yeast Mnl1p in endoplasmic reticulum-associated degradation. J. Biol. Chem. 2009, 284, 11815-11825. [CrossRef]

98. Sokolowska, I.; Pilka, E.S.; Sandvig, K.; Wegrzyn, G.; Slominska-Wojewodzka, M. Hydrophobicity of protein determinants influences the recognition of substrates by EDEM1 and EDEM2 in human cells. BMC Cell Biol. 2015, 16, 1. [CrossRef]

99. Lamriben, L.; Oster, M.E.; Tamura, T.; Tian, W.; Yang, Z.; Clausen, H.; Hebert, D.N. EDEM1's mannosidase-like domain binds ERAD client proteins in a redox-sensitive manner and possesses catalytic activity. J. Biol. Chem. 2018, 293, 13932-13945. [CrossRef] 
100. Ogen-Shtern, N.; Avezov, E.; Shenkman, M.; Benyair, R.; Lederkremer, G.Z. Mannosidase IA is in Quality Control Vesicles and Participates in Glycoprotein Targeting to ERAD. J. Mol. Biol. 2016, 428, 3194-3205. [CrossRef]

101. Sun, Z.; Brodsky, J.I. Protein quality control in the secretory pathway. J. Cell Biol. 2019, 218, 3171-3187. [CrossRef] [PubMed]

102. Ushioda, R.; Miyamoto, A.; Inoue, M.; Watanabe, S.; Okumura, M.; Maegawa, K.I.; Uegaki, K.; Fujii, S.; Fukuda, Y.; Umitsu, M.; et al. Redox-assisted regulation of $\mathrm{Ca}^{2+}$ homeostasis in the endoplasmic reticulum by disulfide reductase ERdj5. Proc. Natl. Acad. Sci. USA 2016, 113, E6055-E6063. [CrossRef] [PubMed]

103. Jarosch, E.; Taxis, C.; Volkwein, C.; Bordallo, J.; Finley, D.; Wolf, D.H.; Sommer, T. Protein dislocation from the ER requires polyubiquitination and the AAA-ATPase Cdc48. Nat. Cell Biol. 2002, 4, 134-139. [CrossRef] [PubMed]

104. Bordallo, J.; Plemper, R.K.; Finger, A.; Wolf, D.H. Der3p/Hrd1p is required for endoplasmic reticulum-associated degradation of misfolded lumenal and integral membrane proteins. Mol. Biol. Cell 1998, 9, 209-222. [CrossRef] [PubMed]

105. Bays, N.W.; Gardner, R.G.; Seelig, L.P.; Joazeiro, C.A.; Hampton, R.Y. Hrd1p/Der3p is a membrane-anchored ubiquitin ligase required for ER-associated degradation. Nat. Cell Biol. 2001, 3, 24-29. [CrossRef] [PubMed]

106. Baldridge, R.D.; Rapoport, T.A. Autoubiquitination of the Hrd1 Ligase Triggers Protein Retrotranslocation in ERAD. Cell 2016, 166, 394-407. [CrossRef]

107. Kadowaki, H.; Satrimafitrah, P.; Takami, Y.; Nishitoh, H. Molecular mechanism of ER stress-induced pre-emptive quality control involving association of the translocon, Derlin-1, and HRD1. Sci. Rep. 2018, 8, 7317. [CrossRef]

108. Leitman, J.; Shenkman, M.; Gofman, Y.; Shtern, N.O.; Ben-Tal, N.; Hendershot, L.M.; Lederkremer, G.Z. Herp coordinates compartmentalization and recruitment of HRD1 and misfolded proteins for ERAD. Mol. Biol. Cell 2014, 25, 1050-1060. [CrossRef]

109. Ye, Y.; Tang, W.K.; Zhang, T.; Xia, D. A Mighty "Protein Extractor" of the Cell: Structure and Function of the p97/CDC48 ATPase. Front. Mol. Biosci. 2017, 4, 39. [CrossRef]

110. Alexandru, G.; Graumann, J.; Smith, G.T.; Kolawa, N.J.; Fang, R.; Deshaies, R.J. UBXD7 binds multiple ubiquitin ligases and implicates p97 in HIF1alpha turnover. Cell 2008, 134, 804-816. [CrossRef]

111. Allen, M.D.; Buchberger, A.; Bycroft, M. The PUB domain functions as a p97 binding module in human peptide N-glycanase. J. Biol. Chem. 2006, 281, 25502-25508. [CrossRef] [PubMed]

112. Mehta, S.G.; Khare, M.; Ramani, R.; Watts, G.D.; Simon, M.; Osann, K.E.; Donkervoort, S.; Dec, E.; Nalbandian, A.; Platt, J.; et al. Genotype-phenotype studies of VCP-associated inclusion body myopathy with Paget disease of bone and/or frontotemporal dementia. Clin. Genet. 2013, 83, 422-431. [CrossRef] [PubMed]

113. Bebeacua, C.; Förster, A.; McKeown, C.; Meyer, H.H.; Zhang, X.; Freemont, P.S. Distinct conformations of the protein complex p97-Ufd1-Npl4 revealed by electron cryomicroscopy. Proc. Natl. Acad. Sci. USA 2012, 109, 1098-1103. [CrossRef] [PubMed]

114. Carvalho, P.; Stanley, A.M.; Rapoport, T.A. Retrotranslocation of a misfolded luminal ER protein by the ubiquitin-ligase Hrd1p. Cell 2010, 143, 579-591. [CrossRef]

115. Ellgaard, L.; Sevier, C.S.; Bulleid, N.J. How Are Proteins Reduced in the Endoplasmic Reticulum? Trends Biochem. Sci. 2018, 43, 32-43. [CrossRef]

116. Oka, O.B.; Pringle, M.A.; Schopp, I.M.; Braakman, I.; Bulleid, N.J. ERdj5 is the ER reductase that catalyzes the removal of non-native disulfides and correct folding of the LDL receptor. Mol. Cell 2013, 50, 793-804. [CrossRef]

117. Grubb, S.; Guo, L.; Fisher, E.A.; Brodsky, J.L. Protein disulfide isomerases contribute differentially to the endoplasmic reticulum-associated degradation of apolipoprotein B and other substrates. Mol. Biol. Cell 2012, 23, 520-532. [CrossRef]

(C) 2020 by the authors. Licensee MDPI, Basel, Switzerland. This article is an open access article distributed under the terms and conditions of the Creative Commons Attribution (CC BY) license (http://creativecommons.org/licenses/by/4.0/). 